Provided for non-commercial research and education use. Not for reproduction, distribution or commercial use.

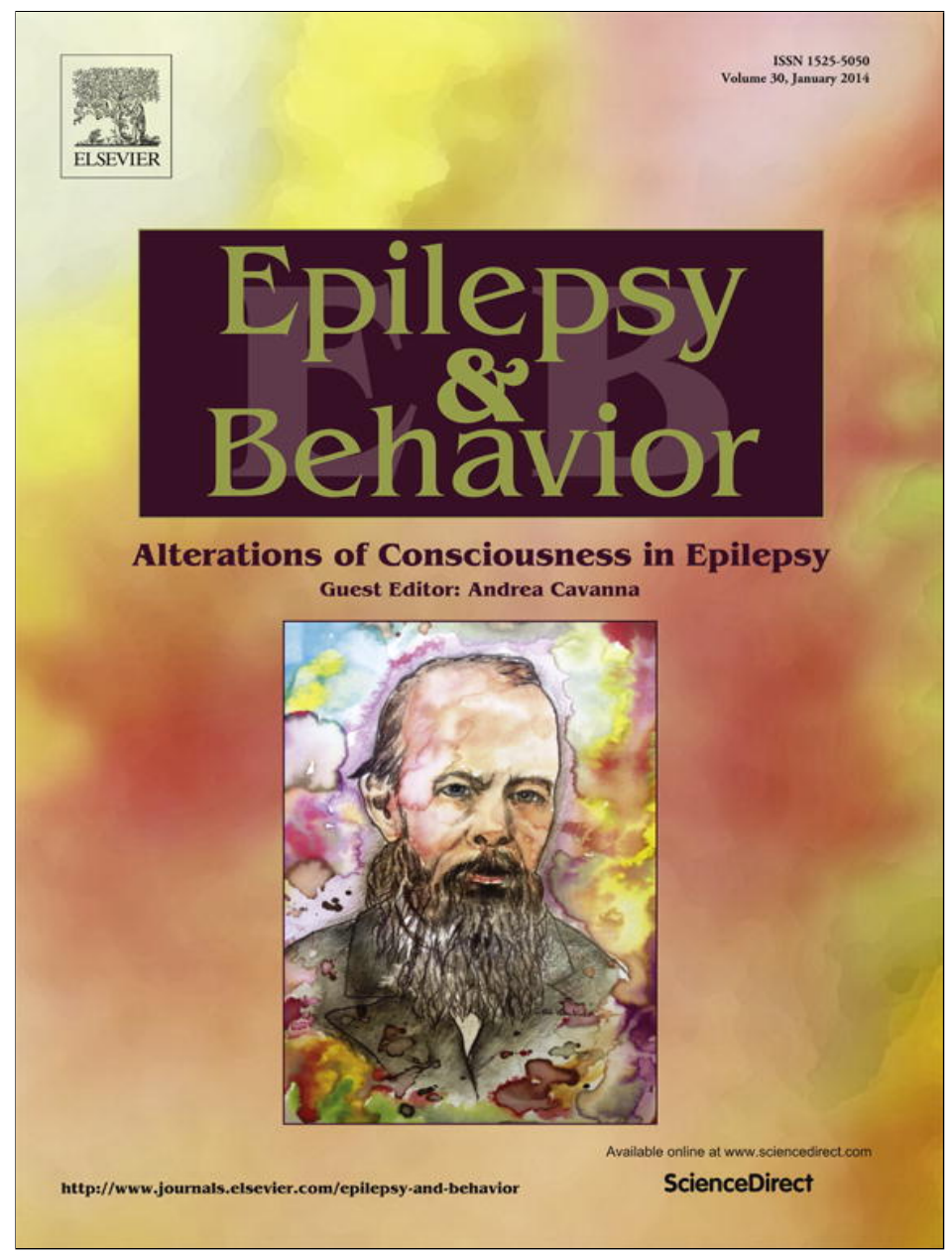

This article appeared in a journal published by Elsevier. The attached copy is furnished to the author for internal non-commercial research and education use, including for instruction at the authors institution and sharing with colleagues.

Other uses, including reproduction and distribution, or selling or licensing copies, or posting to personal, institutional or third party websites are prohibited.

In most cases authors are permitted to post their version of the article (e.g. in Word or Tex form) to their personal website or institutional repository. Authors requiring further information regarding Elsevier's archiving and manuscript policies are encouraged to visit:

http://www.elsevier.com/authorsrights 
Review

\title{
Functional neuroanatomy of disorders of consciousness
}

\author{
Carol Di Perri ${ }^{\mathrm{a}, \mathrm{b}}$, Johan Stender ${ }^{\mathrm{a}, \mathrm{c}}$, Steven Laureys ${ }^{\mathrm{a}}$, Olivia Gosseries ${ }^{\mathrm{a}, *}$ \\ a Coma Science Group, Cyclotron Research Centre E' Neurology Department, University and University Hospital of Liege, Liege, Belgium \\ b Department of Neuroradiology, National Neurological Institute C. Mondino, Pavia, Italy \\ c Department of Neuroscience and Pharmacology, University of Copenhagen, Denmark
}

\section{A R T I C L E I N F O}

\section{Article history:}

Accepted 6 September 2013

Available online 5 October 2013

\section{Keywords:}

Consciousness

Neuroimaging techniques

Brain connectivity

Vegetative/unresponsive wakefulness

syndrome

Minimally conscious state

General anesthesia

Coma

\begin{abstract}
A B S T R A C T
Our understanding of the mechanisms of loss and recovery of consciousness, following severe brain injury or during anesthesia, is changing rapidly. Recent neuroimaging studies have shown that patients with chronic disorders of consciousness and subjects undergoing general anesthesia present a complex dysfunctionality in the architecture of brain connectivity. At present, the global hallmark of impaired consciousness appears to be a multifaceted dysfunctional connectivity pattern with both within-network loss of connectivity in a widespread frontoparietal network and between-network hyperconnectivity involving other regions such as the insula and ventral tegmental area. Despite ongoing efforts, the mechanisms underlying the emergence of consciousness after severe brain injury are not thoroughly understood. Important questions remain unanswered: What triggers the connectivity impairment leading to disorders of consciousness? Why do some patients recover from coma, while others with apparently similar brain injuries do not? Understanding these mechanisms could lead to a better comprehension of brain function and, hopefully, lead to new therapeutic strategies in this challenging patient population.
\end{abstract}

This article is part of a Special Issue entitled Epilepsy and Consciousness.

(c) 2013 Elsevier Inc. All rights reserved.

\section{Introduction}

Consciousness is a multifaceted and ambiguous concept and the focus of both scientific and philosophical debate. Despite ongoing efforts, no universal definition of the term has been agreed on [1,2]. For practical and didactic purposes, consciousness is often described as having two main components: awareness and wakefulness [3]. Awareness refers to the phenomenal perception of self and surroundings or, in the words of Nagel, "the subjective character of experience" [4]. Awareness appears anatomically related to structures in the frontoparietal cortex [3]. At present, there is no single marker of awareness, but its presence can be clinically deduced from behavioral signs such as visual pursuit or responses to command [5]. Wakefulness describes the state of arousal or the potential to experience awareness. It is supported by structures in the brainstem and clinically evidenced by the eyes being open [3]. Wakefulness generally precipitates awareness; an increase in arousal is usually accompanied by an increase of conscious experience, leading to a linear correlation of the two components along the

\footnotetext{
Abbreviations: DOC, disorders of consciousness; VS, vegetative state; UWS, unresponsive wakefulness syndrome; MCS, minimally conscious state; fMRI, functional magnetic resonance imaging; EEG, electroencephalography; TMS, transcranial magnetic stimulation.

* Corresponding author at: Coma Science Group, Cyclotron Research Center and Neurology Department, University and University Hospital of Liege, Sart-Tilman B30, 4000 Liege, Belgium. Fax: + 3243662946.

E-mail address: ogosseries@ulg.ac.be (0. Gosseries).
}

spectrum of consciousness [2]. For example, during deep sleep, coma, and anesthesia, awareness and wakefulness decline simultaneously [3]. In some cases, however, the two are dissociated. On the one hand, during vivid dreams, wakefulness is lowered, whereas internal awareness is preserved. On the other hand, in some pathological states, wakefulness is spared, while awareness is impaired [6-8]. These states comprise the minimally conscious state (MCS) and the vegetative state (VS, now also called the unresponsive wakefulness syndrome - UWS $[9,10])$, as well as absence seizures, complex partial seizures, and somnambulism (Fig. 1). Studies of these dissociated states offer a unique opportunity to disentangle and critically investigate the neural correlates of awareness.

Here, we review the current understanding of (un)consciousness obtained from studies of disorders of consciousness (DOC) following brain injury (coma, VS/UWS, and MCS) and general anesthesia. We focus on functional neuroimaging studies and address the utility of these techniques in the diagnosis of patients with DOC (for a review on electroencephalography - EEG - studies, see [11]).

\section{Disorders of consciousness and neural correlates of awareness}

Disorders of consciousness remain among the most challenging and poorly understood conditions in modern medical care. Patients with VS/UWS are seemingly awake but exhibit no behavioral signs of awareness [3]. Vegetative state/unresponsive wakefulness syndrome typically follows a coma, a state of complete unconsciousness from 


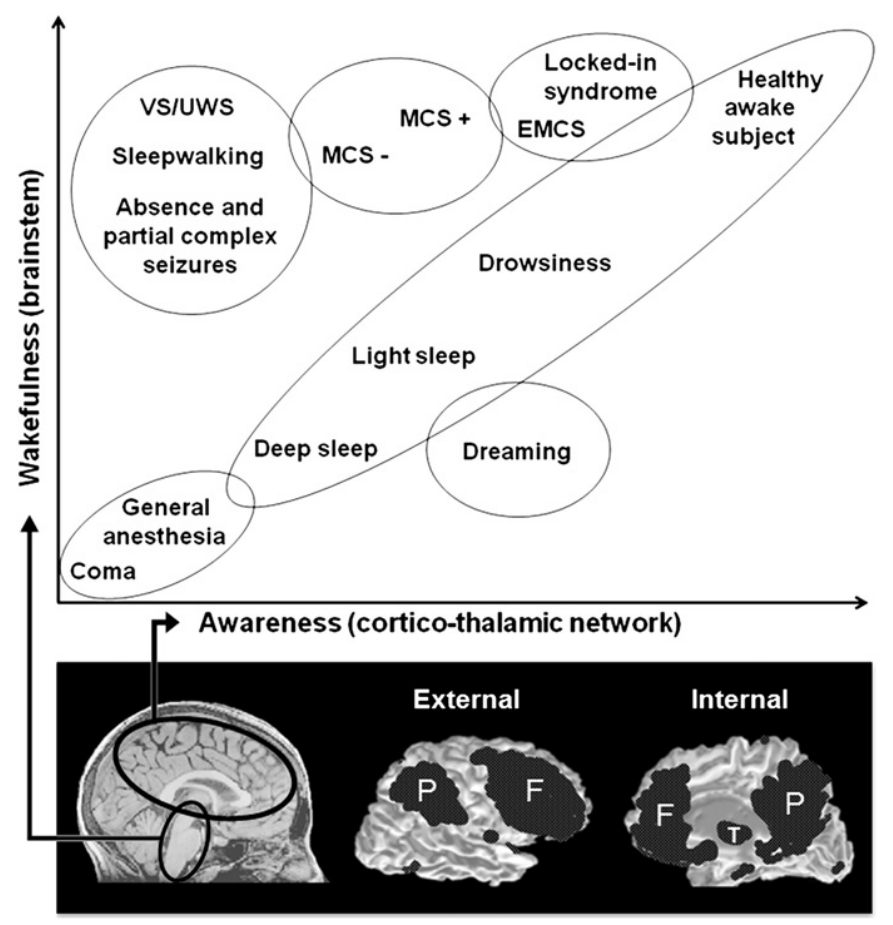

Fig. 1. The two main components of consciousness: wakefulness and awareness. Correlation between wakefulness, related to brainstem ascending reticular activating systems [68], and awareness, related to cortico-thalamic network connectivity. In most physiological, pharmacological, and pathological alterations of consciousness, wakefulness and awareness are positively linearly correlated. In some cases, however, both components of consciousness are dissociated. Vegetative state/unresponsive wakefulness syndrome, VS/UWS; minimally conscious state, MCS; emergence of MCS, EMCS.

Adapted from [3].

which the patient cannot be aroused [12,13]. Minimally conscious state patients show fluctuating awareness and may respond appropriately to some stimuli [14]. Minimally conscious state was recently subcategorized as MCS plus and MCS minus based on the presence or absence, respectively, of language comprehension [15]. Emergence from MCS is defined as the return of reliable communication or functional use of objects [14].

Conventional brain structural imaging studies have shown heterogeneous lesion patterns in DOC, suggesting that no specific brain region can be unequivocally related to awareness [16]. This is supported by observations in transient unconscious states, such as during epileptic seizures, where the core pathology is related to the abnormality of brain function rather than macroscopic structure [17]. Nonetheless, widespread diffuse axonal injury and thalamic damage have been observed in patients with VS/UWS following traumatic brain injury $[18,19]$, supporting the role of the thalamus and cerebral cortex in the genesis of awareness.

Using 18-fluorodesoxyglucose positron emission tomography, a technique which measures brain energy turnover, we showed that awareness is not tightly related to the global brain metabolism [20] but, rather, to the preservation of a large-scale frontoparietal network encompassing the polymodal associative cortices [21]. In line with their clinical condition, patients with MCS show a partial preservation of this large-scale associative frontoparietal network [22]. Similar findings of frontoparietal deactivation have been recorded in somnambulism as well as in absence and complex partial (mainly in the temporal lobe) seizures [6-8], whereas temporal lobe seizures without loss of consciousness are not accompanied by these widespread changes [7].

Connectivity within the frontoparietal regions and their thalamic connections appear to play a key role in the maintenance of consciousness. Thus, reestablishment of thalamocortical activity in a patient with VS/UWS was observed upon recovery [20]. Furthermore, disconnection between primary sensory areas and higher-order associative cortices, which are thought to be required for conscious perception [3], has been demonstrated in patients with VS/UWS during passive auditory and noxious stimulations $[23,24]$.

There is now increasing evidence that this large anatomical frontoparietal cortex contains at least two main functional networks, clearly linked to spontaneous mentation (Fig. 1) [25]. The external awareness network, or executive control network, subserved by lateral frontoparietal regions, shows increasing activity during attentiondemanding cognitive tasks. The internal awareness network, or default mode network (DMN), is a mesial frontoparietal network that appears to be involved in self-related processes [26]. Activity in the two networks is normally anticorrelated - when one is active, the other is not [25]. However, studies using functional magnetic resonance imaging (fMRI) found decreasing anticorrelation in anesthesia [27], deep sleep [28], and VS/UWS [29], showing the anticorrelation to be a core constituent of conscious cognition [30].

Because of its link to internally oriented cognitive content, such as mind-wandering and autobiographical memory recall, the DMN, in particular, has been proposed as the locus of conscious awareness $[25,31,32]$. Resting-state fMRI studies have detected reduced connectivity in the DMN of patients in coma, VS/UWS, and MCS (Fig. 2) [33]. This decrease of connectivity was correlated to the level of consciousness, mostly affecting the precuneus, a brain area considered to be a critical hub within this network with a massive degree of interconnectivity [34]. Similar decreases in DMN connectivity were observed in healthy controls during deep sleep [35], sedation, and general anesthesia (Fig. 2) [27]. Nevertheless, coherent DMN connectivity has also been observed in VS/UWS and anesthetized monkeys [29,36]. This suggests that the DMN may not be a strict reflection of conscious mental activity, and there are indications that the role of the DMN in consciousness is highly complex. Concurrent with decreasing DMN connectivity, we recently reported increased connectivity in the deep structures of the limbic system (i.e., the ventral tegmental area, the insula, the orbitofrontal cortex, and the hypothalamus) in patients with DOC (Fig. 3). The effect was greater in patients with VS/UWS than in patients with MCS [37]. This limbic hyperconnectivity may reflect the persistent engagement of residual neural activity in self-reinforcing neural loops which may disrupt normal patterns of connectivity, including synchronized neural activity in DMN. A loss of connectivity is, therefore, not necessarily the global hallmark of impaired consciousness but only an aspect of a multifaceted dysfunction in the architecture of brain connectivity [37]. Correspondingly, patients with complex partial seizures due to temporal lobe epilepsy associated with mesial sclerosis show increased regional synchronization in areas outside the DMN, such as the ipsilateral parahippocampal gyrus, midbrain, insula, corpus callosum, bilateral sensorimotor cortex, and frontoparietal subcortical structures [38]. Although these findings were detected during interictal periods, they might still support more complex connectivity interplay in the emergence of consciousness.

\section{Detection of awareness in disorders of consciousness}

Detection of potential awareness in uncommunicative braindamaged patients raises important ethical and medical concerns regarding end-of-life decisions and palliative treatment [5]. At present, the gold standard to assess the level of consciousness is behavioral assessment [5]. Lack of behavioral responsiveness does not, however, imply absence of consciousness. Clinical studies have shown that up to $40 \%$ of patients with a diagnosis of VS/UWS may, in fact, retain some level of awareness [39-41]. The main causes of misdiagnosis are associated with patient's disabilities such as paralysis or aphasia, confusion of terminology, and the use of nonstandardized diagnostic methods [42]. Even with the best clinical assessment, the level of awareness in patients with DOC can still be underestimated [43]. Indeed, neuroimaging 


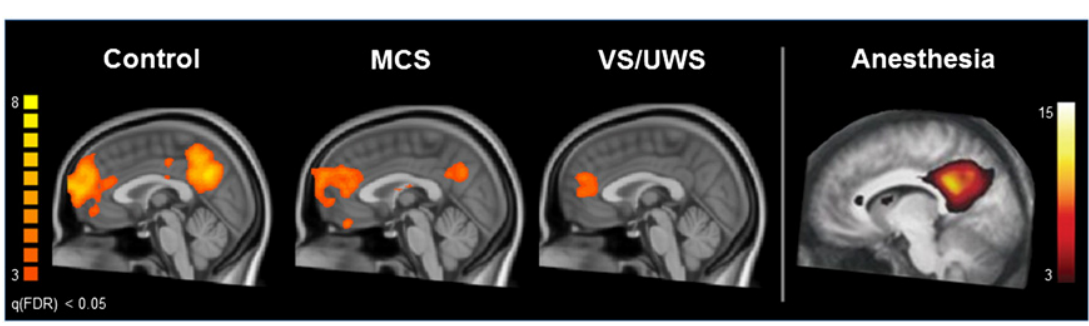

Fig. 2. Default mode network (DMN) connectivity in vegetative state/unresponsive wakefulness syndrome (VS/UWS), minimally conscious state (MCS), healthy controls, and during general anesthesia using propofol. The DMN spatial map is only partially preserved in VS/UWS, MCS, and during anesthesia. Results from independent component analysis (ICA). Adapted from [27,37].

studies have detected residual cognition and awareness in some patients with VS/UWS. In one exceptional case, it was even possible to establish two-way communication. The researchers asked the noncommunicative patient to "imagine playing tennis" to respond "yes" and "imagine walking into your house" to respond "no" to biographical questions during an fMRI scanning session [44].

Unfortunately, fMRI-based communication is impractical. The fact that a scanner is needed limits its use to a hospital setting and precludes application in patients with metal implants or in critical condition in intensive care. Active command paradigms combined with EEG [45-47] or electromyography [48] are more wieldy solutions, which have already permitted the detection of voluntary brain function in patients with VS/UWS and enabled functional communication with patients with complete locked-in syndrome (i.e., fully conscious but completely paralyzed including eye movement [49]).

These methods may, in principle, be used as a differential diagnostic tool, since active compliance by the patient unequivocally proves the presence of conscious awareness. However, diagnostic paradigms relying on the patients' active collaboration present significant drawbacks.

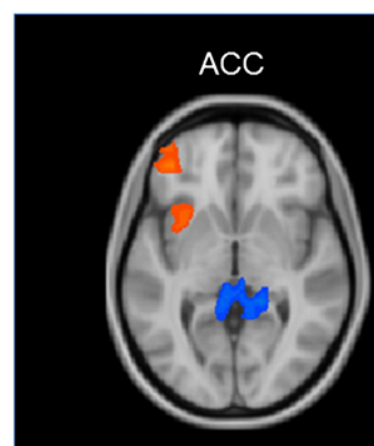

Hippocampus

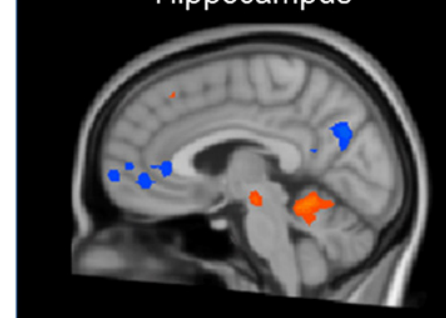

PCC

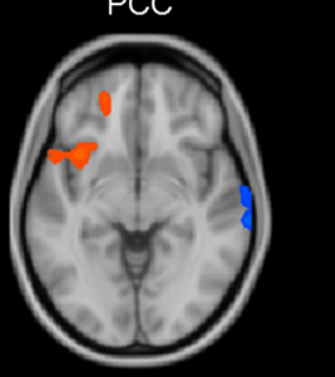

VTA

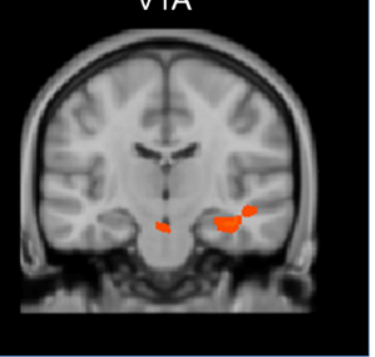

Fig. 3. Brain disconnectivity in patients with vegetative state/unresponsive wakefulness syndrome (VS/UWS). In vegetative state/unresponsive wakefulness syndrome (VS/ UWS), the anterior cingulate cortex (ACC) and posterior cingulate cortex (PCC) are hypoconnected to the default mode network (DMN, in blue) and hyperconnected to the frontoinsular cortex (in red). The hippocampus is hyperconnected to the ventral tegmental area (VTA) and cerebellum (in red) and hypoconnected to the DMN (in blue). Correlation from random effect $(p<0.01)$ and clustered-corrected $(p<0.05)$ results based on general linear model maps with seed region of interest comparing patients with VS/ UWS to healthy controls.

Adapted from [37]
The risk of false negatives is high, and even patients with MCS often fail to comply [50]. This may be due to several reasons. For example, a patient may not have understood the task instructions because of deafness, aphasia, or fluctuating levels of consciousness [43]. Methods that can detect consciousness without the collaboration of the patients are therefore needed. Transcranial magnetic stimulation combined with EEG (TMS-EEG) is a promising approach. This technique allows noninvasive stimulation of a subset of cortical neurons, measuring the effects of the perturbation across the cortex [51]. Stimulation of a superficial region of the cerebral cortex of patients with VS/UWS with TMS has been shown to either induce no response or trigger a simple, local EEG response, indicating a breakdown of effective connectivity [52,53], similar to that observed in deep sleep and anesthesia $[54,55]$. In contrast, in patients with MCS, TMS triggered complex EEG activations which sequentially involved distant cortical areas, similar to activations recorded in locked-in patients, in healthy awake subjects, and during vivid dreams [53,54,56]. Interestingly, a patient with MCS assessed during a period of no responsiveness still showed complex and widespread brain responses to TMS, even though no conscious behavior could be observed at the bedside [53].

\section{Unconsciousness in general anesthesia}

General anesthesia is a reversible state of unconsciousness. As the dosage can be controlled, it provides a unique opportunity to explore the correlates of (un)consciousness in its different stages. General anesthesia is induced by pharmacological drugs that provoke loss of consciousness, immobilization, and analgesia with concomitant stability of the autonomic, cardiovascular, respiratory, and thermoregulatory systems [57]. Despite routine clinical use and ongoing investigations of the cellular effects, no consensus has yet been reached on how the anesthetics induce alterations of consciousness [58]. However, some progress has recently been made showing hypnotic anesthetic agents that target specific brain sites, the function of which is hierarchically altered in a dose-dependent manner [58]. Unlike sleep, the primum movens which occurs in brainstem structures [59], the primary site of action for hypnotic agents, is believed to be at the cortical level, with secondary involvement of the brainstem [57]. Inhibitory anesthetic agents cause a widespread decrease of resting cerebral metabolism as well as reduced brain activations in response to external stimuli (especially in the cortex, thalamus, and midbrain) [60,61].

Being the most extensively studied anesthetic agent, we review here the research on the effects of propofol (for an extensive review on other anesthestic agents, see $[62,63])$. Functional magnetic resonance imaging studies have shown that propofol-induced anesthesia is associated with decreased corticocortical and thalamocortical connectivity in higher-order brain networks including frontoparietal networks (i.e., executive control network and DMN) and the salience network [27,64]. In contrast, functional connectivity in low-level sensory cortices (i.e., auditory and visual networks [27]) appears relatively preserved, in line with previous observations in patients with DOC [24]. In addition, both DMN activity and cross-modal interaction between auditory and visual networks could be correlated to the level of consciousness [27]. However, a recent EEG study found unchanged thalamocortical connectivity 
during propofol anesthesia, while a decrease of corticocortical connectivity was still observed, especially in backward connections between the frontal and parietal cortices [65]. These results suggest that propofol induces a breakdown in brain functional integration, modifying both within- and between-network connectivity $[27,61]$.

Besides decreasing activity in the higher-order brain areas of the cortex, increase of connectivity has also been observed in other brain regions during sedation [66], as already observed in patients with DOC. Mild sedation with propofol increased thalamic excitability [65] and increased connectivity between the pontine tegmental area and the insulae [64]. Specifically, increased connectivity between the thalamus and the auditory, insular, and sensorimotor cortices has also been reported under propofol-induced anesthesia [64]. Altogether, these findings support the hypothesis of a complex brain connectivity architecture in the emergence of consciousness and demonstrate the importance of considering functions of a brain region in terms of its functional integration rather than segregation [67].

\section{Conclusions}

In the last decade, the progress of neuroimaging techniques has led to substantial developments in our understanding of consciousness. Novel applications of functional neuroimaging have provided important insights into the pathophysiology of DOC and enabled new diagnostic approaches. Studies in both DOC and anesthesia have shown that altered states of consciousness are related to a complex dysfunctionality in the connectivity architecture of the brain. Breakdown of connectivity within the frontoparietal associative networks and increased connectivity between networks involving subcortical structures appear to be involved. Nevertheless, all answers lead to new questions, and it is clear that our current insights are just the tip of the iceberg. A deeper understanding of the physiology of consciousness may help provide patients with DOC with better diagnosis and treatment. Hopefully, this knowledge will ultimately lead to therapy which may be able to restore consciousness in this challenging patient population.

\section{Conflict of interest}

The authors declare that there are no conflicts of interest.

\section{Acknowledgments}

This study was funded by the Belgian National Funds for Scientific Research (FNRS), Fonds Léon Fredericq, James S. McDonnell Foundation, Mind Science Foundation, European Commission, Concerted Research Action, Public Utility Foundation "Université Européenne du Travail" and "Fondazione Europea di Ricerca Biomedica". OG is a postdoctoral researcher, and SL is research director at FNRS. Dr. Carol Di Perri is supported by a grant from the Italian Ministry of Health (GR-20091493804). We thank Ziggy Kennell for English revision.

\section{References}

[1] Zeman A. Consciousness. Brain 2001;124(Pt 7):1263-89.

[2] Cavanna AE, Ali F. Epilepsy: the quintessential pathology of consciousness. Behav Neurol 2011;24(1):3-10.

[3] Laureys S. The neural correlate of (un)awareness: lessons from the vegetative state. Trends Cogn Sci 2005;9(12):556-9.

[4] Nagel T, Nagel T. What is it like to be a bat? Philos Rev 1974;83(4):435-50.

[5] Boly M, Massimini M, Garrido MI, Gosseries O, Noirhomme Q Laureys S, et al. Brain connectivity in disorders of consciousness. Brain Connect 2012;2(1):1-10.

[6] Salek-Haddadi A, Lemieux L, Merschhemke M, Friston KJ, Duncan JS, Fish DR. Functional magnetic resonance imaging of human absence seizures. Ann Neurol 2003:53(5):663-7.

[7] Blumenfeld H, McNally KA, Vanderhill SD, Paige AL, Chung R, Davis K, et al. Positive and negative network correlations in temporal lobe epilepsy. Cereb Cortex 2004;14(8): 892-902.

[8] Bassetti C, Vella S, Donati F, Wielepp P, Weder B. SPECT during sleepwalking. Lancet 2000;356(9228):484-5.
[9] Laureys S, Celesia GG, Cohadon F, Lavrijsen J, Leon-Carrion J, Sannita WG, et al. Unresponsive wakefulness syndrome: a new name for the vegetative state or apallic syndrome. BMC Med 2010;8:68.

[10] Gosseries O, Bruno MA, Chatelle C, Vanhaudenhuyse A, Schnakers C, Soddu A, et al. Disorders of consciousness: what's in a name? NeuroRehabilitation 2011;28(1):3-14.

[11] Lehembre R, Gosseries O, Lugo Z, Jedidi Z, Chatelle C, Sadzot B, et al. Electrophysiological investigations of brain function in coma, vegetative and minimally conscious patients. Arch Ital Biol 2012;150(2-3):122-39.

[12] Plum F, Posner JB. The diagnosis of stupor and coma. Contemp Neurol Ser 1972;10: $1-286$.

[13] Bernat JL. Chronic disorders of consciousness. Lancet 2006;367(9517):1181-92.

[14] Giacino JT, Ashwal S, Childs N, Cranford R, Jennett B, Katz DI, et al. The minimally conscious state: definition and diagnostic criteria. Neurology 2002;58(3):349-53.

[15] Bruno MA, Majerus S, Boly M, Vanhaudenhuyse A, Schnakers C, Gosseries O, et al. Functional neuroanatomy underlying the clinical subcategorization of minimally conscious state patients. J Neurol 2012;259(6):1087-98.

[16] Tshibanda L, Vanhaudenhuyse A, Bruno MA, Boly M, Soddu A, Laureys S, et al. [MRI in coma survivors] Rev Med Liege 2009;64 [Spec No:42-8. Imagerie par resonance magnetique chez des patients survivant a un coma. fre].

[17] Blumenfeld H. Impaired consciousness in epilepsy. Lancet Neurol 2012;11(9):814-26.

[18] Adams JH, Graham DI, Jennett B. The neuropathology of the vegetative state after an acute brain insult. Brain 2000;123(Pt 7):1327-38.

[19] Graham DI, Adams JH, Murray LS, Jennett B. Neuropathology of the vegetative state after head injury. Neuropsychol Rehabil 2005;15(3-4):198-213.

[20] Laureys S, Lemaire C, Maquet P, Phillips C, Franck G. Cerebral metabolism during vegetative state and after recovery to consciousness. J Neurol Neurosurg Psychiatry 1999;67(1):121.

[21] Laureys S, Goldman S, Phillips C, Van Bogaert P, Aerts J, Luxen A, et al. Impaired effective cortical connectivity in vegetative state: preliminary investigation using PET. Neuroimage 1999;9(4):377-82.

[22] Laureys S, Perrin F, Faymonville ME, Schnakers C, Boly M, Bartsch V, et al. Cerebral processing in the minimally conscious state. Neurology 2004;63(5):916-8.

[23] Laureys S, Faymonville ME, Peigneux P, Damas P, Lambermont B, Del Fiore G, et al Cortical processing of noxious somatosensory stimuli in the persistent vegetative state. Neuroimage 2002;17(2):732-41.

[24] Laureys S, Faymonville ME, Degueldre C, Fiore GD, Damas P, Lambertmont B, et al. Auditory processing in the vegetative state. Brain 2000;123(8):1589-601

[25] Vanhaudenhuyse A, Demertzi A, Schabus M, Noirhomme Q, Bredart S, Boly M, et al. Two distinct neuronal networks mediate the awareness of environment and of self. J Cogn Neurosci 2011;23(3):570-8.

[26] Fox MD, Snyder AZ, Vincent JL, Corbetta M, Van Essen DC, Raichle ME. The human brain is intrinsically organized into dynamic, anticorrelated functional networks. Proc Natl Acad Sci U S A 2005;102(27):9673-8.

[27] Boveroux P, Vanhaudenhuyse A, Bruno MA, Noirhomme Q, Lauwick S, Luxen A, et al. Breakdown of within- and between-network resting state functional magnetic resonance imaging connectivity during propofol-induced loss of consciousness. Anesthesiology 2010;113(5):1038-53.

[28] Samann PG, Wehrle R, Hoehn D, Spoormaker VI, Peters H, Tully C, et al. Development of the brain's default mode network from wakefulness to slow wave sleep. Cereb Cortex 2011;21(9):2082-93.

[29] Boly M, Tshibanda L, Vanhaudenhuyse A, Noirhomme Q, Schnakers C, Ledoux D, et al. Functional connectivity in the default network during resting state is preserved in a vegetative but not in a brain dead patient. Hum Brain Mapp 2009;30(8):2393-400.

[30] Heine L, Soddu A, Gomez F, Vanhaudenhuyse A, Tshibanda L, Thonnard M, et al. Resting state networks and consciousness: alterations of multiple resting state network connectivity in physiological, pharmacological, and pathological consciousness states. Front Psychol 2012;3:295.

[31] Raichle ME, MacLeod AM, Snyder AZ, Powers WJ, Gusnard DA, Shulman GL. A default mode of brain function. Proc Natl Acad Sci U S A 2001;98(2):676-82.

[32] Schilbach L, Eickhoff SB, Rotarska-Jagiela A, Fink GR, Vogeley K. Minds at rest? Social cognition as the default mode of cognizing and its putative relationship to the "default system" of the brain. Conscious Cogn 2008;17(2):457-67.

[33] Vanhaudenhuyse A, Noirhomme Q Tshibanda LJ, Bruno MA, Boveroux P, Schnakers $C$, et al. Default network connectivity reflects the level of consciousness in noncommunicative brain-damaged patients. Brain 2010;133(Pt 1):161-71.

[34] Cavanna AE. The precuneus and consciousness. CNS Spectr 2007;12(7):545-52.

[35] Greicius MD, Kiviniemi V, Tervonen O, Vainionpaa V, Alahuhta S, Reiss AL, et al. Persistent default-mode network connectivity during light sedation. Hum Brain Mapp 2008;29(7):839-47.

[36] Vincent JL, Patel GH, Fox MD, Snyder AZ, Baker JT, Van Essen DC, et al. Intrinsic functional architecture in the anaesthetized monkey brain. Nature 2007:447(7140):83-6

[37] Di Perri C, Bastianello S, Bartsch A, Pistarini C, Maggioni G, Magrassi L, et al. Limbic hyperconnectivity in the vegetative state. Neurology 2013;81:1-8.

[38] Zeng H, Pizarro R, Nair VA, La C, Prabhakaran V. Alterations in regional homogeneity of resting-state brain activity in mesial temporal lobe epilepsy. Epilepsia 2013;54(4): 658-66.

[39] Schnakers C, Vanhaudenhuyse A, Giacino J, Ventura M, Boly M, Majerus S, et al. Diagnostic accuracy of the vegetative and minimally conscious state: clinical consensus versus standardized neurobehavioral assessment. BMC Neurol 2009;9:35.

[40] Andrews K, Murphy L, Munday R, Littlewood C. Misdiagnosis of the vegetative state: retrospective study in a rehabilitation unit. BMJ 1996;313(7048):13-6.

[41] Childs NL, Mercer WN, Childs HW. Accuracy of diagnosis of persistent vegetative state. Neurology 1993;43(8):1465-7.

[42] Giacino JT, Kalmar K, Whyte J. The JFK Coma Recovery Scale-Revised: measurement characteristics and diagnostic utility. Arch Phys Med Rehabil 2004;85(12):2020-9. 
[43] Monti MM, Laureys S, Owen AM. The vegetative state. BMJ 2010;341:c3765.

[44] Monti MM, Vanhaudenhuyse A, Coleman MR, Boly M, Pickard JD, Tshibanda L, et al Willful modulation of brain activity in disorders of consciousness. N Engl J Med 2010;362(7):579-89.

[45] Schnakers C, Perrin F, Schabus M, Hustinx R, Majerus S, Moonen G, et al. Detecting consciousness in a total locked-in syndrome: an active event-related paradigm Neurocase 2009;15(4):271-7.

[46] Lule D, Noirhomme Q Kleih SC, Chatelle C, Halder S, Demertzi A, et al. Probing command following in patients with disorders of consciousness using a brain-computer interface. Clin Neurophysiol 2013;124(1):101-6.

[47] Cruse D, Chennu S, Chatelle C, Bekinschtein TA, Fernandez-Espejo D, Pickard JD, et al. Bedside detection of awareness in the vegetative state: a cohort study. Lancet 2011;378(9809):2088-94.

[48] Bekinschtein TA, Coleman MR, Niklison III J, Pickard JD, Manes FF. Can electromyography objectively detect voluntary movement in disorders of consciousness? J Neurol Neurosurg Psychiatry 2008;79(7):826-8

[49] Bauer G, Gerstenbrand F, Rumpl E. Varieties of the locked-in syndrome. J Neurol 1979;221(2):77-91.

[50] Bardin JC, Fins JJ, Katz DI, Hersh J, Heier LA, Tabelow K, et al. Dissociations between behavioural and functional magnetic resonance imaging-based evaluations of cognitive function after brain injury. Brain 2011;134(Pt 3):769-82.

[51] Massimini M, Boly M, Casali A, Rosanova M, Tononi G. A perturbational approach for evaluating the brain's capacity for consciousness. Prog Brain Res 2009;177:201-14.

[52] Ragazzoni A, Pirulli C, Veniero D, Feurra M, Cincotta M, Giovannelli F, et al. Vegetative versus minimally conscious states: a study using TMS-EEG, sensory and eventrelated potentials. PLoS One 2013;8(2):e57069.

[53] Rosanova M, Gosseries O, Casarotto S, Boly M, Casali AG, Bruno MA, et al. Recovery of cortical effective connectivity and recovery of consciousness in vegetative patients. Brain 2012;135(Pt 4):1308-20.

[54] Massimini M, Ferrarelli F, Huber R, Esser SK, Singh H, Tononi G. Breakdown of cortical effective connectivity during sleep. Science 2005;309(5744):2228-32.

[55] Ferrarelli F, Massimini M, Sarasso S, Casali A, Riedner BA, Angelini G, et al. Breakdown in cortical effective connectivity during midazolam-induced loss of consciousness. Proc Natl Acad Sci U S A 2010;107(6):2681-6.
[56] Massimini M, Ferrarelli F, Murphy M, Huber R, Riedner B, Casarotto S, et al. Cortical reactivity and effective connectivity during REM sleep in humans. Cogn Neurosci 2010;1(3):176-83.

[57] Brown EN, Lydic R, Schiff ND. General anesthesia, sleep, and coma. N Engl J Med 2010;363(27):2638-50.

[58] Bonhomme V, Boveroux P, Brichant JF, Laureys S, Boly M. Neural correlates of consciousness during general anesthesia using functional magnetic resonance imaging (fMRI). Arch Ital Biol 2012;150(2-3):155-63.

[59] Lydic R, Baghdoyan HA. Sleep, anesthesiology, and the neurobiology of arousal state control. Anesthesiology 2005;103(6):1268-95.

[60] Campagna JA, Miller KW, Forman SA. Mechanisms of actions of inhaled anesthetics. N Engl J Med 2003;348(21):2110-24.

[61] Schrouff J, Perlbarg V, Boly M, Marrelec G, Boveroux P, Vanhaudenhuyse A, et al. Brain functional integration decreases during propofol-induced loss of consciousness. Neuroimage 2011;57(1):198-205.

[62] Grasshoff C, Rudolph U, Antkowiak B. Molecular and systemic mechanisms of general anaesthesia: the 'multi-site and multiple mechanisms' concept. Curr Opin Anaesthesiol 2005;18(4):386-91.

[63] Solt K, Forman SA. Correlating the clinical actions and molecular mechanisms of general anesthetics. Curr Opin Anaesthesiol 2007;20(4):300-6.

[64] Guldenmund P, Vanhaudenhuyse A, Boly M, Laureys S, Soddu A. A default mode of brain function in altered states of consciousness. Arch Ital Biol 2012;150(2-3): 107-21.

[65] Boly M, Moran R, Murphy M, Boveroux P, Bruno MA, Noirhomme Q et al Connectivity changes underlying spectral EEG changes during propofol-induced loss of consciousness. J Neurosci 2012;32(20):7082-90.

[66] Velly LJ, Rey MF, Bruder NJ, Gouvitsos FA, Witjas T, Regis JM, et al. Differential dynamic of action on cortical and subcortical structures of anesthetic agents during induction of anesthesia. Anesthesiology 2007;107(2):202-12.

[67] Seghier ML, Zeidman P, Neufeld NH, Leff AP, Price CJ. Identifying abnormal connectivity in patients using dynamic causal modeling of fMRI responses. Front Syst Neurosci 2010:4.

[68] Fuller PM, Scherman D, Pedersen NP, Saper CB, LU J. Reassessment of the structural basis of the ascending arousal system. J Comp Neurol 2011;519(5):933-56. 